\title{
Comparison of efficacy of labetalol and methyldopa in patients with pregnancy-induced hypertension
}

\author{
Vaidehi Subhedar*, Saunitra Inamdar, C. Hariharan, Siddharth Subhedar
}

Department of Obstetrics \& Gynecology, JNMC, Sawangi (M), Wardha, Maharashtra, India

Received: 4 December 2012

Accepted: 6 January 2013

*Correspondence:

Dr. Vaidehi Subhedar

E-mail: vaidehisubhedar@gmail.com

\begin{abstract}
Background: In a country like India, where maternal mortality rate is still very high despite progress and development which has consistently been made in the health services, a big proportion is still deprived of it. Hypertension is the most common medical problem encountered during pregnancy. It is estimated that globally 6-8\% of pregnancies are complicated by hypertension. Antihypertensive drugs are often used to lower blood pressure with the aim of preventing its progression to adverse outcomes for the mother and the fetus. The risk of developing severe hypertension is reduced to half by using antihypertensive medications. Hence, this study was planned to assess and compare efficacy of labetalol and methyldopa in controlling blood pressure in patients with PIH and to study maternal and perinatal outcome in rural Indian population.

Methods: 180 patients with PIH were divided in to two groups randomly. After randomization, group A received methyldopa $250 \mathrm{mg}$ tid and group B received labetalol 100mg tid. Mean Arterial pressure (MAP) was calculated according to formula systolic BP +2 diastolic BP /3. Patients were subjected to 6 hrly BP monitoring. Comparison of two drugs was done daily by calculating MAP of two groups. Following Observations were made as regards Fall in BP with Labetalol/ Methyldopa, Time required to control BP, Average dose of drugs required to control BP, Onset of labour-spontaneous/induced, Bishop score at induction of labour, Side effects of drugs.

Results: Significant fall in MAP was seen in patients receiving Labetalol. Mean time required to control B.P in group A was 42.22 hours and in group B it was 36.97 hours. Mean Bishop score at induction in present study in group A was 8.27 and in group B was 9.33 with a statistically significant $p<0.05$. (33.33\%) patients went in spontaneous labour in group A while in group B, 23 patients i.e. (48.94\%) patients went in spontaneous labour.

Conclusions: The freedom from maternal and fetal side-effects, the efficient hypotensive action indicates that labetalol is suitable for use during pregnancy.
\end{abstract}

Keywords: Pregnancy, Hypertension, Labetalol, Methyldopa, Efficacy

\section{INTRODUCTION}

In a country like India, where maternal mortality rate is still very high despite progress and development which has consistently been made in the health services, a big proportion is still deprived of it. The analyses of causes of maternal deaths highlight the fact that majority of these deaths are preventable. Hypertensive disorders seem to complicate approximately 10 per cent of pregnancies and are important causes of maternal and fetal morbidity and mortality. ${ }^{1}$ Hypertension is the most common medical problem encountered during pregnancy. $^{2}$ It is estimated that globally $6-8 \%$ of pregnancies are complicated by hypertension. ${ }^{3}$ It is said that preeclampsia and eclampsia contribute to death of a woman every 3 minutes worldwide. ${ }^{2,4}$

Today, though oral medications are available and widely used for the treatment of PIH, the physicians still have to deal with many challenges.

Antihypertensive drugs are often used to lower blood pressure with the aim of preventing its progression to adverse outcomes for the mother and the fetus. The risk of developing severe hypertension is reduced to half by using antihypertensive medications. ${ }^{5}$ Severe hypertension is treated to prevent severe maternal complications. ${ }^{6}$ Methyldopa, labetalol and long-acting nifedipine are 
acceptable oral antihypertensive agents if drug therapy is required in pregnant women with mild to moderate hypertension.

This study was planned to assess and compare efficacy of labetalol and methyldopa in controlling blood pressure in patients with PIH and to study maternal and perinatal outcome in rural Indian population.

\section{Aim and Objectives}

1. Comparison of efficacy of labetalol and methyldopa in controlling blood pressure in patients with PIH.

2. To study maternal and perinatal outcome.

\section{METHODS}

This study was conducted in the Department of Obstetrics and Gynaecology, JAWAHARLAL NEHRU MEDICAL COLLEGE, Sawangi, [Meghe], Wardha over a period of 2 years from September 2010 to September 2012 after taking ethical committee clearance.

Population being investigated: Pregnancy Induced Hypertensive women after 20 weeks of pregnancy coming to AVBRH Sawangi (Meghe) Wardha over a period of 2 years on IPD basis from September 2010 to September 2012.

Sample size: 180 patients of $\mathrm{PIH}$, of which 90 were given Labetalol and 90 were given Methyldopa. Patients were selected for study by subjecting to following: (i) History (ii) Clinical Examination: General and systemic examination.

Inclusion criteria: Diagnosed PIH patients based on criteria- BP more than $140 / 90 \mathrm{mmHg}$ on two separate occasion 6 hours apart, Proteinuria 1+ dipstick in two midstream urine samples collected 4 hours apart, and after 20 weeks of pregnancy till term.

Exclusion criteria: Multifetal pregnancy, eclampsia, and women with preexisting or concurrent medical disorders like diabetes mellitus, cardiac diseases, renal disease, thyrotoxicosis, hemophilia and chronic hypertension attributable to hypertension during their pregnancy.

Patients were divided in to two groups randomly. After randomization, group A received methyldopa $250 \mathrm{mg}$ tid and group B received labetalol 100mg tid. Mean Arterial pressure (MAP) was calculated according to formula systolic $\mathrm{BP}+2$ diastolic $\mathrm{BP} / 3^{8}$

Patients were subjected to 6 hourly BP monitoring. Comparison of two drugs was done daily by calculating MAP of two groups. If there was no fall in BP even after 48 hrs of drug therapy, dose of the drug was doubled. Response in lowering BP was assessed over a period of 7 days. Observations were made as regards fall in BP with labetalol/ methyldopa, time required to control BP, average dose of drugs required to control BP, onset of labour-spontaneous/induced, Bishop score at induction of labour and side effects of drugs.

The results thus obtained were subjected to standard statistical analysis and analyzed using the Chi-square test. A $p$ value of less than 0.05 was considered statistically significant.

\section{RESULTS}

According to Figure 1, among the total 180 patients, maximum number of patients that is 92 patients belonged to the age group of 15 to 24 years: 48 patients $(53.33 \%)$ in Group A and 44 patients (48.89\%) in Group B. The mean age of the patients in Group A was 24.41 yrs and in group B was $24.85 \mathrm{yrs}$. The mean age was statistically nonsignificant in both the groups. Figure 2 states that in the present study, 102 patients were primigravidae, 53 patients $(58.89 \%)$ in methyldopa group and 49 patients $(54.44 \%)$ in labetalol group. The difference between the two groups was statistically nonsignificant.

Table 1 shows comparison of MAP in both the groups at Day 1 and Day 7. In the present study, the mean arterial pressure in patients treated with methyldopa on admission was $109.86 \mathrm{mmHg}$, while on day 7 it reduced to $98.15 \mathrm{mmHg}$, with a statistically significant $p$ value $<0.05$. With labetalol, the mean arterial pressure on admission was $109.48 \mathrm{mmHg}$ which reduced to $96.90 \mathrm{mmHg}$ on day 7. Reduction in MAP was statistically significant. On comparing the two drugs, MAP on admission were comparable but on day 7 , significant fall in MAP was seen in patients receiving labetalol.

Table 2 shows comparison of time to control BP in both the groups. In the present study, the mean time required to control BP in group A was 42.22 hours and in group B it was 36.97 hours. The difference between the two groups was statistically significant with labetalol showing earlier control of BP than methyldopa.

Figure 3 shows the mean dose required to control BP in group A was $1111.11 \mathrm{mg}$. In group A, 40 patients (44.4\%) required a dose of $750 \mathrm{mg} /$ day to achieve optimal BP control. Out of remaining 40 patients, 20 patients $(22.2 \%)$ required a dose of $1000 \mathrm{mg} /$ day to achieve optimal BP control while remaining 20 patients $(22.2 \%)$ required a dose of $1500 \mathrm{mg} /$ day .10 patients had to take $2000 \mathrm{mg}$ /day to achieve optimal B.P control.

Figure 4 says in group B the mean dose required was $382.22 \mathrm{mg}$. 50 patients $(55.6 \%)$ had their BP controlled with $300 \mathrm{mg} /$ day. 20 patients $(22.2 \%)$ required a dose of $400 \mathrm{mg} /$ day. Of remaining 20 patients, 10 patients $(11.1 \%)$ required a dose of $500 \mathrm{mg} /$ day and 10 patients $(11.1 \%)$ required a dose of $600 \mathrm{mg} /$ day. 


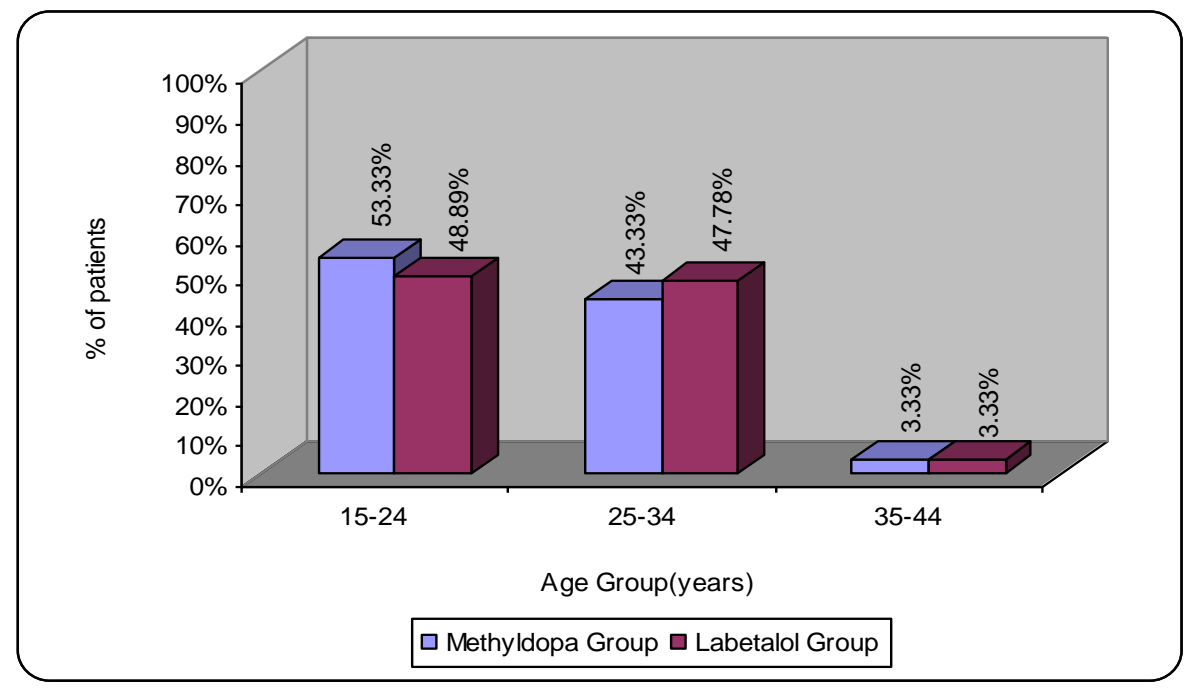

Figure 1: Age wise distribution of patients in both the groups.

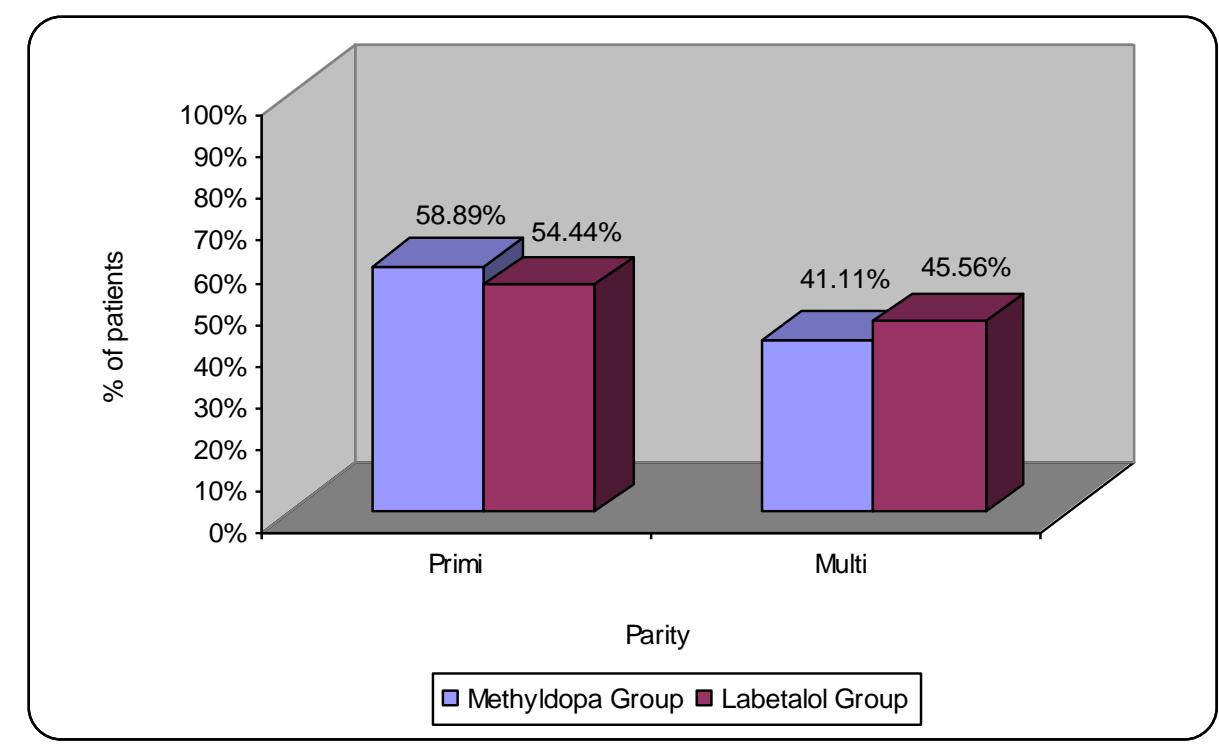

Figure 2: Distribution of patients according to gravidity in both the groups.

Table 1: Comparison of MAP in both the groups at Day 1 and Day 7.

\begin{tabular}{|c|c|c|c|c|c|c|c|}
\hline & Group & $\mathbf{N}$ & Mean [mmHg] & $\begin{array}{l}\text { Std. } \\
\text { Deviation }\end{array}$ & $\begin{array}{l}\text { Mean } \\
\text { Difference }\end{array}$ & Z-value & $p$-value \\
\hline \multirow{2}{*}{ Day 1} & Methyldopa & 90 & 109.86 & 2.91 & \multirow{2}{*}{$0.37 \pm 0.42$} & \multirow{2}{*}{0.88} & \multirow{2}{*}{$\begin{array}{l}0.37 \\
\mathrm{NS}, p>0.0\end{array}$} \\
\hline & Labetalol & 90 & 109.49 & 2.78 & & & \\
\hline \multirow{2}{*}{ Day 7} & Methyldopa & 90 & 98.15 & 3.44 & \multirow{2}{*}{$1.24 \pm 0.46$} & \multirow{2}{*}{2.68} & \multirow{2}{*}{$\begin{array}{l}0.008 \\
\mathrm{~S}, p<0.05\end{array}$} \\
\hline & Labetalol & 90 & 96.90 & 2.70 & & & \\
\hline
\end{tabular}


Table 2: Comparison of Time to control BP in both the groups.

\begin{tabular}{|c|c|c|c|c|c|c|}
\hline Group & $\mathbf{N}$ & $\begin{array}{l}\text { Mean } \\
\text { [hours] }\end{array}$ & Std. Deviation & $\begin{array}{l}\text { Std. Error } \\
\text { Mean }\end{array}$ & Z-value & $p$-value \\
\hline Methyldopa & 90 & 42.22 & 3.04 & 0.32 & \multirow[t]{2}{*}{11.74} & \multirow[t]{2}{*}{$\begin{array}{c}0.000 \\
\mathrm{~S}, p<0.05\end{array}$} \\
\hline Labetalol & 90 & 36.97 & 2.94 & 0.31 & & \\
\hline
\end{tabular}

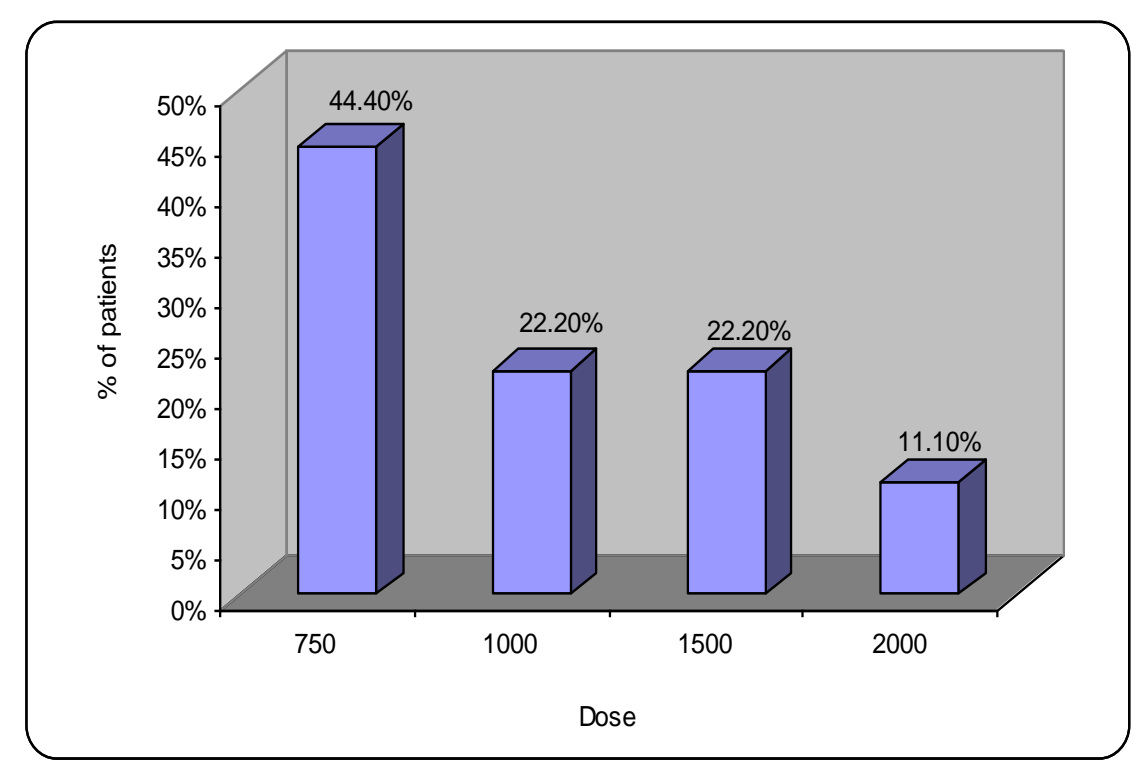

Figure 3: Distribution of patients according to dose in methyldopa group.

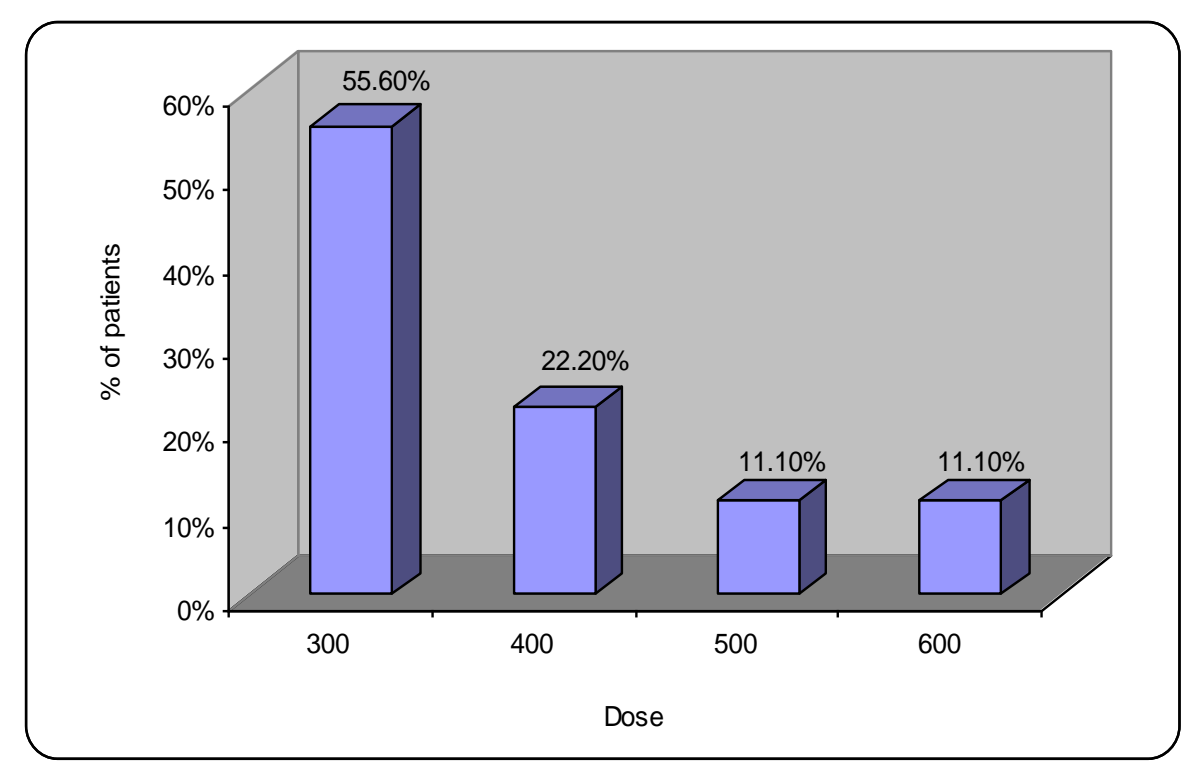

Figure 4: Distribution of patients according to dose in labetalol group.

In the present study 9 patients in group A went in spontaneous labour while 18 patients were induced. In group B 23 patients went in spontaneous labour and 24 patients were induced these values were found to be 
statistically significant $p<0.05$. Thus the rate of spontaneous labour was more in patients treated with labetalol. This may be accounted to the fact that labetalol has ripening effect on the cervix. These results are depicted in Figure 5.

Figure 6 depicts comparison of Bishop Score in both the groups. Mean Bishop score at induction in present study in group A was 8.27 and in group B was 9.33 with a statistically significant $p<0.05$.
Figure 7 depicts distribution of patients according to side effects. In the present study, most common side-effect observed was headache. 10 patients in Group A and 8 patients in group B had this symptom. The other sideeffects included drowsiness, more in patients treated with methyldopa, weakness, more in patients treated with labetalol. The incidence of side-effects such as nausea, vomiting, myalgia was similar in both the groups.

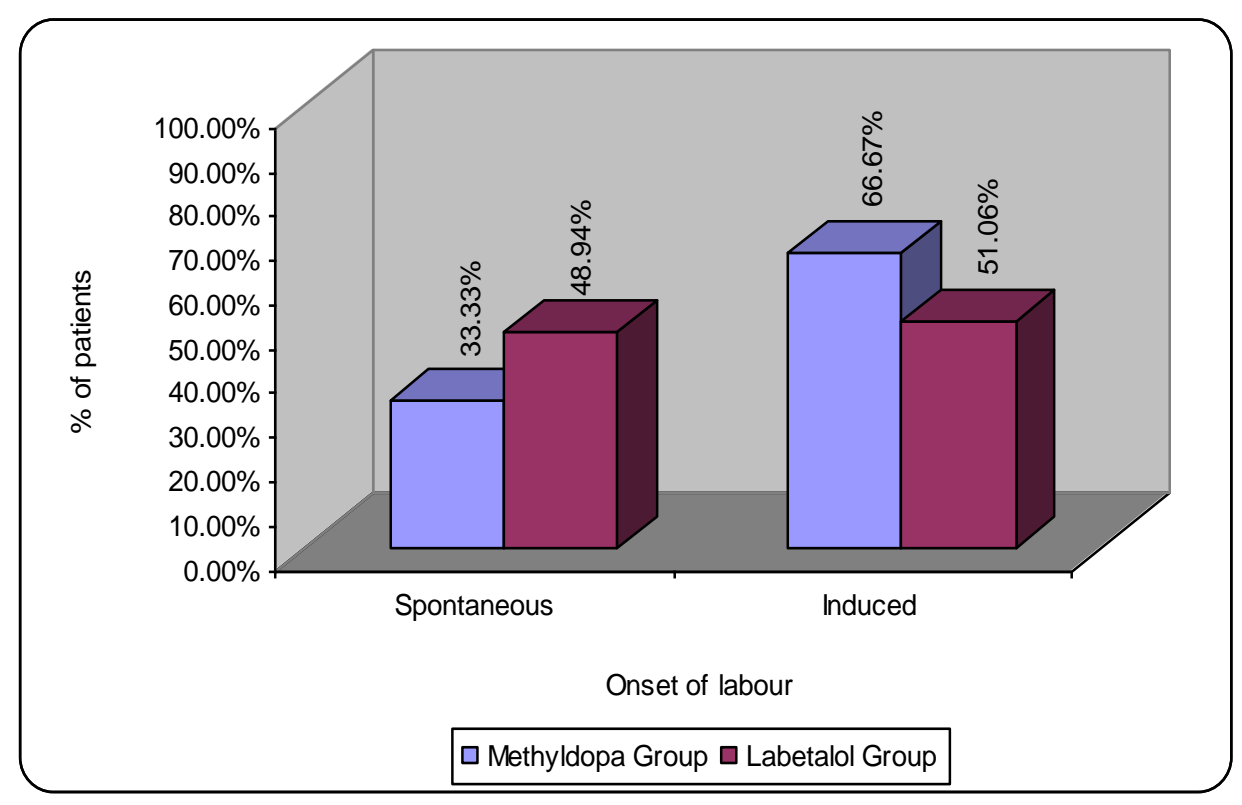

Figure 5: Distribution of patients according to onset of labour who delivered vaginally.

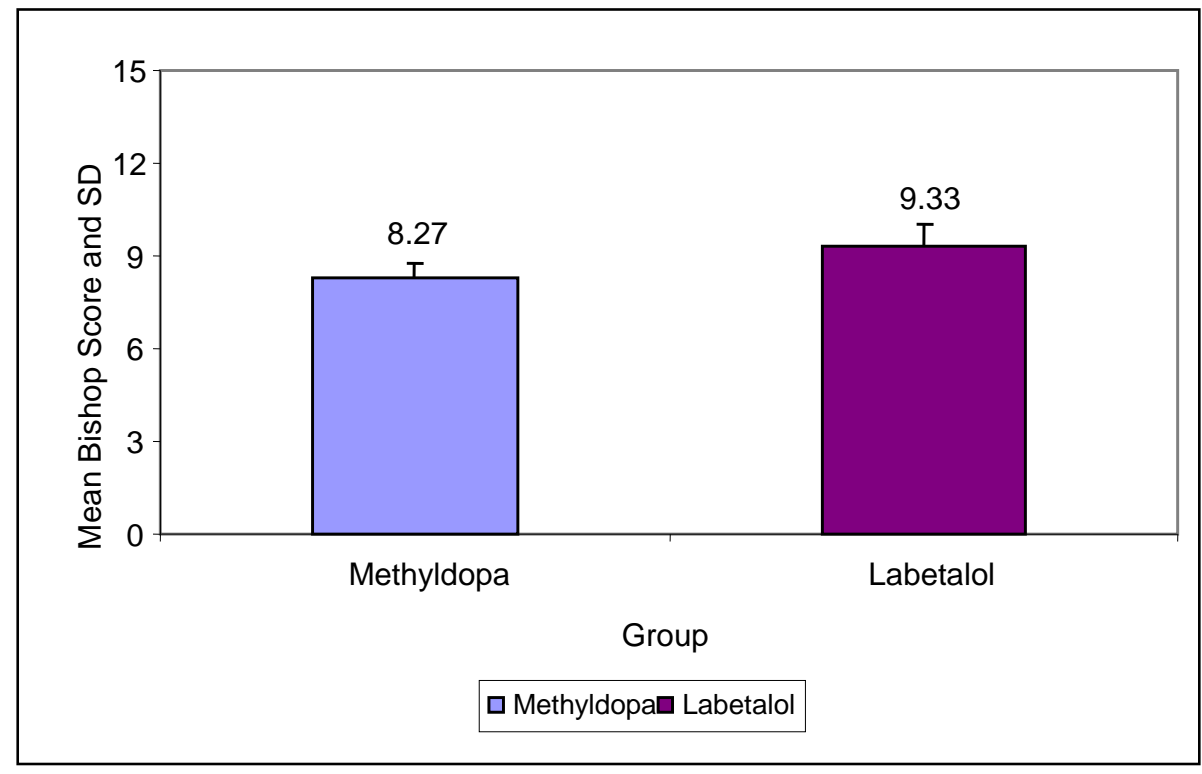

Figure 6: Comparison of Bishop Score in both the groups. 


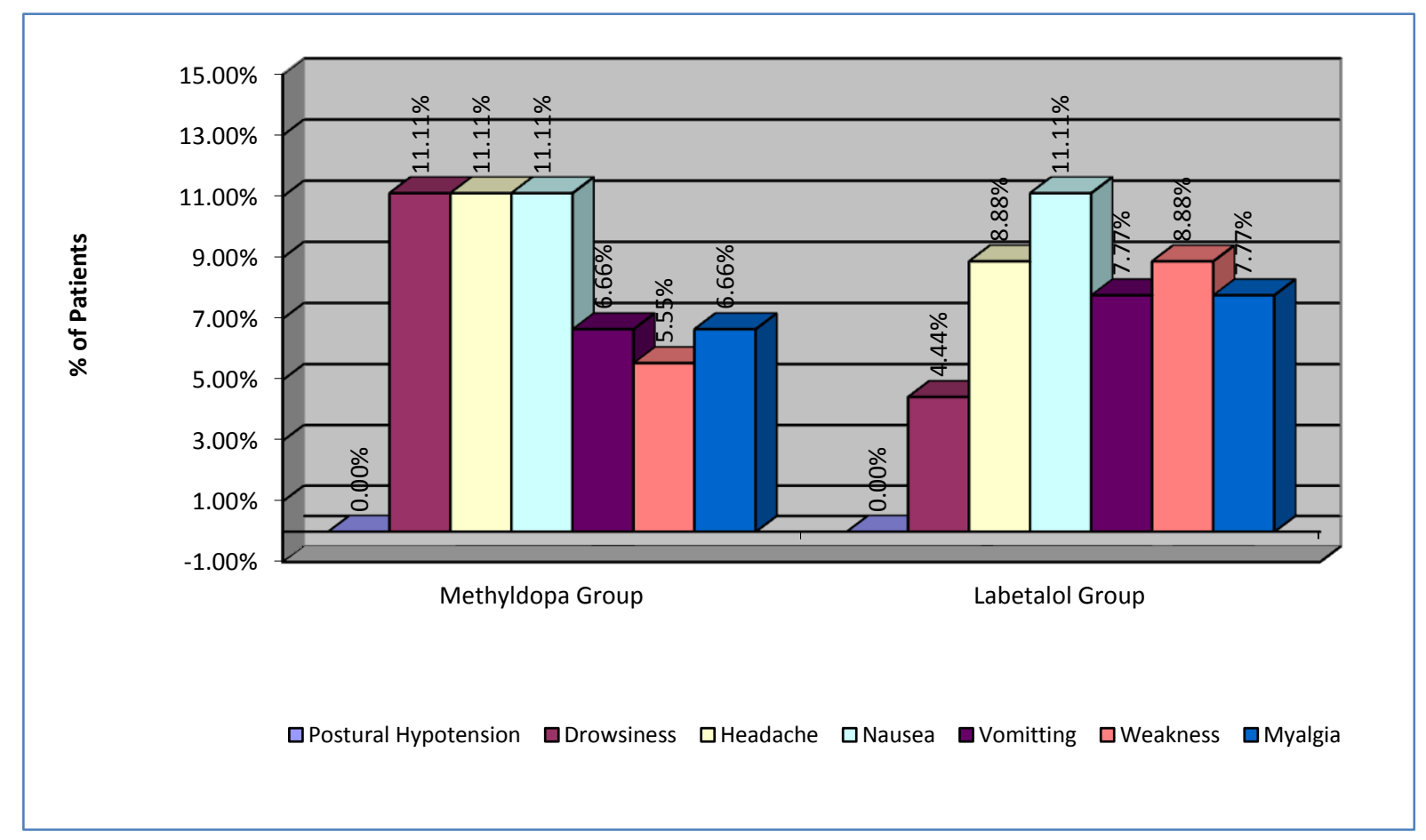

Figure 7: Distribution of patients according to side effects.

\section{DISCUSSION}

Among the total 180 patients in the present study, maximum number of patients in both the groups, group $\mathrm{A}$ [Methyldopa] and group B [Labetalol], were in the age group of 15 to 24 years. Gravidity distribution showed maximum patients of $\mathrm{PIH}$ as primigravidae in both the groups.

In the present study, the mean arterial pressure in patients treated with methyldopa on admission was $109.86 \mathrm{mmHg}$, while on day 7 it reduced to $98.15 \mathrm{mmHg}$, with a statistically significant $p$ value $<0.05$. With labetalol, the mean arterial pressure on admission was $109.48 \mathrm{mmHg}$ which reduced to $96.90 \mathrm{mmHg}$ on day 7 . Reduction in MAP was statistically significant. On comparing the two drugs, MAP on admission were comparable but on day 7, significant fall in MAP was seen in patients receiving labetalol.

According to a study conducted by Lamming et al, the average MAP in both groups was same before treatment. There was a highly significant fall in MAP in the group treated with labetalol $(p<0.001)$ but no significant fall was noted in the group tested with methyldopa $(p>0.05){ }^{8}$ In a similar study conducted by El Qarmalawi et al, $81.4 \%$ patients in labetalol group had a significant fall in MAP as against $68.5 \%$ in patients taking methyldopa. ${ }^{9}$
In the present study, the mean time required to control BP in group A was 42.22 hours and in group B it was 36.97 hours. The difference between the two groups was statistically significant with labetalol showing earlier control of BP than methyldopa.

In a study conducted by Sanders et al, the average time to achieve optimal B.P control was similar in both the groups. ${ }^{10}$

D.J. Cruickshank, et al $^{11}$ observed that Labetalol did control the blood pressure in 45 of the 51 treated women (88\%) within 24 hrs. The rapid control of blood pressure with oral labetalol achieving a satisfactory response in $88 \%(45 / 51)$ of cases within $24 \mathrm{~h}$ is an obvious advantage. It is interesting that several other workers have found similar response rates - Lardoux's group $82 \%$, CA Michael $92 \% .^{12,13}$

Marked fall of both systolic and diastolic pressure generally between 24 and 48 hours from the start of using methyldopa was noticed by S. F. Hans. ${ }^{14}$

The mean dose required to control B.P in group A was $1111.11 \mathrm{mg}$. In group $\mathrm{A}, 40$ patients $(44.4 \%)$ required a dose of $750 \mathrm{mg} /$ day to achieve optimal B.P control. Out of remaining 40 patients, 20 patients $(22.2 \%)$ required a dose of $1000 \mathrm{mg} /$ day to achieve optimal B.P control while remaining 20 patients $(22.2 \%)$ required a dose of 
$1500 \mathrm{mg} /$ day .10 patients had to take $2000 \mathrm{mg} /$ day to achieve optimal BP control.

In group B the mean dose required was $382.22 \mathrm{mg}$. 50 patients $(55.6 \%)$ had their BP controlled with $300 \mathrm{mg} /$ day. 20 patients $(22.2 \%)$ required a dose of $400 \mathrm{mg} / \mathrm{day}$. Of remaining 20 patients, 10 patients $(11.1 \%)$ required a dose of $500 \mathrm{mg} /$ day and 10 patients $(11.1 \%)$ required a dose of $600 \mathrm{mg} /$ day.

In a study conducted by Sanders et al maintenance doses for labetalol and methyldopa averaged $810 \mathrm{mg} /$ day and $1183 \mathrm{mg} /$ day respectively. In present study the average dose of labetalol required to achieve optimal B.P control was much less than in above mentioned study, but for methyldopa doses were comparable. ${ }^{10}$

Lardoux's group found that the average daily dose of labetalol required for satisfactory blood pressure control was $600 \mathrm{mg}^{12}$

In the present study, 9 patients in group A $(33.33 \%)$ went in spontaneous labour while 18 patients $(66.67 \%)$ were induced. In group B, 23 patients $(48.94 \%)$ went in spontaneous labour and 24 patient's (51.06\%) were induced. These values were found to be statistically significant with $\mathrm{p}<0.05$. Thus the rate of spontaneous labour was more in patients treated with labetalol. This may be accounted to the fact that labetalol has ripening effect on the cervix.

The observation made by Qarmalawi et al suggest higher incidence of spontaneous onset of labour in the labetalol group. ${ }^{9}$ Lamming et al too reported a higher incidence of spontaneous labour in the labetalol group. ${ }^{8}$

Mean Bishop score at induction in present study in group A was 8.27 and in group B was 9.33 with a statistically significant $\mathrm{p}<0.05$. Lamming et al reported a higher Bishop score of 10 in patients treated with labetalol as compared to a mean Bishop score of 7.1 in patients treated with methyldopa. ${ }^{8}$

In the present study, most common side-effect observed was headache. 10 patients in Group $\mathrm{A}$ and 8 patients in group $\mathrm{B}$ had this symptom. The other side-effects included drowsiness, more in patients treated with methyldopa, weakness, more in patients treated with labetalol. The incidence of side-effects such as nausea, vomiting, myalgia was similar in both the groups.

Study conducted by Verma et al states that adverse events observed were lower in the labetalol treated group compared to the methyldopa group. ${ }^{15}$ In a study by Qarmalawi et al, patients receiving methyldopa complained of side-effects such as drowsiness (22.2\%), headache $(14.8 \%)$, nasal congestion $(7.4 \%)$, postural hypotension $(5.6 \%))^{9} 6$ patients in labetalol group complained of dyspnoea, no other side-effects were noticed.

\section{CONCLUSIONS}

Present study showed that labetalol is more advantageous than methyldopa in terms of better and quicker control of blood pressure. The chances of spontaneous onset of labour were greater in the labetalol group than in the methyldopa group. Those patients on labetalol, who required induction of labour were noted to have a better Bishop score at the time of induction. The freedom from maternal and fetal side-effects, the efficient hypotensive action and consequent improved perinatal mortality in a condition usually accompanied by high fetal loss, indicate that labetalol is suitable for use during pregnancy. The only limiting factor in use of labetalol is economic constraints among rural population of India.

Funding: No funding sources

Competing interests: There are no competing interests to declare

Ethical approval: The study was approved by the Institutional ethics committee

\section{REFERENCES}

1. Chauhan R, Sharma RS, Parashar MK, Chauhan VS. Clinical examination of hypertension in pregnancy. In: Shah MR, editor. Hypertensive disorders in pregnancy: 1st ed. New Delhi: Jaypee Brothers Medical Publishers (P) Ltd; 2007. p. 11125.

2. Arias F, Daftary SN, Bhide AG. Hypertensive disorders of pregnancy. In: Dasgupta S, Nasim S, Khanna M, editors. Practical guide to high-risk pregnancy and delivery-a South Asian perspective: 3rd ed. New Delhi: Elsevier Publication; 2008. p. 397-439.

3. Magee LA, Ornstein MP, Dadelszen P. Fortnightly review: management of hypertension in pregnancy. BMJ 1999;318:1332-6.

4. Shah MR. PIH: The Challenge. In: Shah MR, editor. Hypertensive disorders in pregnancy: 1st ed. New Delhi: Jaypee Brothers Medical Publishers (P) Ltd; 2007. p.19.

5. Abalos E, Duley L, Steyn DW, Henderson-Smart DJ, et al. Antihypertensive drug therapy for mild to moderate hypertension during pregnancy. Cochrane Database Syst Rev 2007;(1):CD002252.

6. Podymow T, August P. Update on the use of antihypertensive drugs in pregnancy. Hypertension 2008;51:960-9.

7. Brown MA, Hague WM, Higgins $J$, et al. The detection, investigation and management of hypertension in pregnancy: executive summary. Consensus statement from the Australasian Society for the Study of Hypertension in Pregnancy. Aust N Z J Obstet Gynaecol 2000;40:133-8.

8. Lamming GD \& Symonds EM. Use of Labetalol and Methyldopa in Pregnancy-Induced Hypertension. Br J Clin Pharmacol. 1979; 8:217S$22 \mathrm{~S}$. 
9. El-Qarmalawi AM, Morsy AH, al-Fadly A, Obeid A, Hashem M, et al. Labetalol vs. methyldopa in the treatment of pregnancy-induced hypertension. Int $\mathbf{J}$ Gynaecol Obstet 1995;49:125-30.

10. Sanders GL, Davies DM, Gales GM, Rao JG, Rawlins MD, Routledge PA. A comparative study of methyldopa and labetalol in the treatment of hypertension. Br J Clin Pharmacol 1979;8:149S$51 \mathrm{~S}$.

11. Cruickshank DJ, Robertson AA, Campbell DM, MacGillivray I. Does labetalol influence the development of proteinuria in pregnancy hypertension? A randomised controlled study. Eur J Obstet Gynecol Reprod Biol 1992;45:47-51.

12. Lardoux H, Gerard J, Blazquez G, Chouty F, Flouvat B. Hypertension in pregnancy: evaluation of the two B-blockers atenalol and labetalol. Eur Heart J 1983;4(Suppl G):35-40.

13. Michael CA. Use of labetalol in the treatment of severe hypertension during pregnancy. Br J Clin Pharmacol 1979;8:211S-5S.

14. Hans SF, Kopelman H. Methyldopa in treatment of severe toxaemia of pregnancy. BMJ 1964;1:736-9.

15. Verma R, Lahon K, Tonpay SD, Kale VJ, Jain DK. A comparative randomised controlled parallel group study of efficacy and tolerability of labetalol versus methyldopa in the treatment of new onset hypertension during pregnancy. Int $\mathrm{J}$ Life Sci Pharma Res 2012;2:L23-31.

DOI: $10.5455 / 2320-1770 . i j r \operatorname{cog} 20130205$

Cite this article as: Subhedar V, Inamdar S, Hariharan C, Subhedar S. Comparison of efficacy of labetalol and methyldopa in patients with pregnancy-induced hypertension. Int $\mathbf{J}$ Reprod Contracept Obstet Gynecol 2013;2:27-34. 